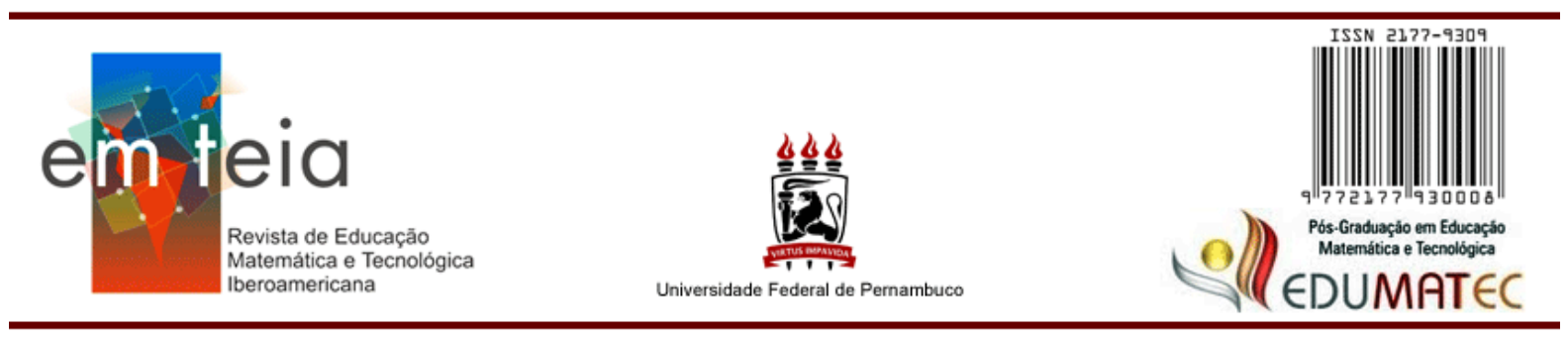

\title{
POTENCIALIDADES DE UMA SEQUENCIA PARA ENSINAR AS MEDIDAS DE TENDÊNCIA CENTRAL NOS ANOS INICIAIS DO ENSINO FUNDAMENTAL
}

\section{Potentialities of a didactical sequence to teach measures of central tendency in the early school years}

\author{
Irene Mauricio Cazorla \\ Doutora em Educação pela Universidade Estadual de Campinas \\ Universidade Estadual de Santa Cruz - Bahia - Brasil \\ icazorla@uol.com.br \\ http://orcid.org/0000-0003-3028-5513 \\ Sandra Maria Pinto Magina \\ Doutora em Educação Matemática pela Universidade de Londres \\ Universidade Estadual de Santa Cruz - Bahia - Brasil \\ sandramagina@gmail.com \\ http://orcid.org/0000-0003-0383-9744
}

Cláudio Vitor Santana Mestre em Educação em Ciências e Matemática pela Universidade Estadual de Santa Cruz Colégio Estadual de Educação Profissional em Biotecnologia e Saúde - Bahia - Brasil

clvitor@yahoo.com.br

\section{Resumo}

http://orcid.org/0000-0002-6830-871X

As medidas de tendência central (MTC) - Moda, Mediana e Média - são fundamentais no processo de sumarização de dados, na compreensão de características dos fenômenos e no auxílio na tomada de decisões. Por essa razão, seu ensino tem sido objeto de investigação, em especial nos anos iniciais da escolarização. Um dos problemas enfrentados se deve à forma abstrata como essas são apresentadas às crianças, que ainda estão no processo de letramento matemático. Neste artigo analisamos as potencialidades e limitações, do ponto de vista teórico, de uma sequência para ensinar as MTC nos anos iniciais do Ensino Fundamental, construída percorrendo as fases do ciclo investigativo, em que as crianças recolhem e analisam seus próprios dados utilizando o cubo estatístico como um material concreto manipulável para representar e trabalhar as MTC. Como referencial teórico para dar suporte as MTC, nos apoiamos na Teoria dos Campos Conceituais (TCC). Trata-se de uma reflexão teórica a partir das evidências de trabalhos correlatos. Espera-se que essas reflexões encorajem os professores e pesquisadores na busca por metodologias que possibilitem às crianças vivenciar e acompanhar a transformação dos dados brutos nessas estatísticas, dando-lhes sentido, e se apropriem desse campo conceitual tão importante na formação estatística dos estudantes.

Palavras-Chave: Medidas de Tendências Central. Anos iniciais. Ciclo Investigativo. Cubo estatístico. 


\begin{abstract}
The Central Tendency Measures - Mode, Median and Mean -, are fundamental in the process of summarizing data, in understanding the characteristics of the phenomena and in assisting in decision making. For this reason, its teaching has been the object of investigation, especially in the early years of schooling. One of the problems faced is due to the abstract way in which these are presented to children, who are still in the process of mathematical literacy. In this article we analyze the potentialities and limitations, from the theoretical point of view, of a sequence to teach TCM in the early years, built by going through the phases of the investigative cycle in which children collect and analyze their own data, using the statistical cube as a tool. manipulable concrete material to represent and work the TCM. As a theoretical framework to support the TCM we support the Conceptual Fields Theory (CFT). It is a theoretical reflection based on the evidence of related works. It is hoped that these reflections will encourage teachers and researchers to search for methodologies that enable children to experience and monitor the transformation of raw data into these statistics, giving them meaning and appropriating this conceptual field so important in the statistical formation of students.
\end{abstract}

Keywords: Central Tendency Measures. Elementary School. Investigative Cycle. Statistical cube.

\title{
Introdução
}

Os conteúdos de Estatística na Educação Básica, no Brasil, foram inseridos oficialmente a partir de 1997, com a publicação dos Parâmetros Curriculares Nacionais (BRASIL, 1997, 1998), no componente curricular de Matemática. Relativamente ao ensino das Medidas de Tendência Central - MTC, os PCN já mencionavam seu uso de forma explícita nos conteúdos conceituais e procedimentais para o $2^{\circ}$ ciclo (equivalente ao $4^{\circ}$ e $5^{\circ}$ anos atuais) do Ensino Fundamental, no bloco Tratamento da Informação: “Obtenção e interpretação de média aritmética" (BRASIL, 1997, p. 61); no $3^{\circ}$ ciclo (6 $6^{\circ}$ e $7^{\circ}$ anos): “Compreensão do significado da média aritmética como um indicador da tendência de uma pesquisa" (BRASIL, 1998, p. 74); e para o $4^{\circ}$ ciclo ( $8^{\circ}$ e $9^{\circ}$ anos): “Obtenção das medidas de tendência central de uma pesquisa (média, moda e mediana), compreendendo seus significados para fazer inferências" (BRASIL, 1998, p. 90).

Recentemente, a Base Nacional Comum Curricular - BNCC (BRASIL, 2018) ratificou essas orientações, agora como uma unidade temática da Matemática, denominada de "Probabilidade e Estatística". Com relação às MTC, a base elenca competências a partir do $7^{\circ}$ ano, como a EF07MA35: "Compreender, em contextos significativos, o significado de média estatística como indicador da tendência de uma pesquisa, calcular seu valor e relacioná-lo, intuitivamente, com a amplitude do conjunto de dados" (p. 311); a EF08MA25: "Obter os valores de medidas de tendência central de uma pesquisa estatística (média, moda e mediana) com a compreensão de seus significados e relacioná-los com a dispersão de dados, indicada pela amplitude" (p. 315); e a EM13MAT316: "Resolver e elaborar problemas, em diferentes 
contextos, que envolvem cálculo e interpretação das medidas de tendência central (média, moda, mediana) e das medidas de dispersão (amplitude, variância e desvio padrão)" (p. 537). Podemos observar que o ensino das MTC deve estar atrelado ao ensino das medidas de dispersão, no intuito de compreender a distribuição dos dados, isto é, compreender de forma mais global o comportamento da variável em estudo.

Infelizmente, as MTC não foram incluídas como objeto de conhecimento a ser ensinado nos anos iniciais. Todavia, advogamos seu ensino desde uma perspectiva intuitiva e lúdica e, o mais importante, desde uma perspectiva inferencial, isto é, levando a criança a se apropriar do real significado das MTC e como, a partir delas, pode verificar se suas conjecturas fazem sentido ou não, aguçando sua curiosidade e desenvolvendo sua capacidade de argumentação.

Contudo, estudos como os de Cobo (2003), Andrade (2013) e Figueiredo (2017) mostram que não é simples trabalhar com as MTC, em especial nos anos iniciais, e isso, ao nosso ver, deve-se à falta de compreensão da própria natureza da Estatística. Ensinar as MTC de forma descontextualizada, focando apenas os procedimentos, pode até levar ao domínio procedimental dessas medidas, mas não propicia a compreensão de seus significados.

Oliveira (2020) mostra que licenciandos em Matemática, iniciantes e veteranos (próximos a se graduarem), ainda apresentam dificuldades na escolha da melhor MTC em uma situação concreta, pois, para isso, os estudantes precisariam conhecer suas propriedades.

Os resultados das pesquisas indicam que um dos principais problemas é saber para que servem as MTC, e isso depende do contexto em que os dados foram gerados e do objetivo da investigação, isto é, saber qual era sua finalidade. Por exemplo, calcular a média da quantidade de letras do primeiro nome é uma tarefa mecânica, mas, conjecturar se os nomes das meninas são mais curtos do que os nomes dos meninos desafia as crianças a comparar ambos os grupos de nomes. Mas, como fariam isso? Nesse contexto, as crianças são desafiadas a encontrar alguma forma de organização, de contagem, de agrupamento dos dados, até chegarem em um número que sintetize os dados e, assim, possam tomar uma decisão. Esse é o papel das MTC.

Nesse sentido, o desafio é colocar as crianças no centro da investigação. Nesse sentido, vários autores mostram como as crianças dos anos iniciais podem ser envolvidas em atividades de Estatística, como Buehring (2006), Souza (2007), Cazorla, Magina, Gitirana e Guimarães (2017) e Alsina, Vásquez, Muñiz-Rodriguez e Rodriguez-Muñiz (2020). Uma das formas é recorrer ao ciclo investigativo, proposto por Wild e Pfannkuch (1999).

Outro aspecto importante é auxiliar a criança a perceber como os dados brutos vão se transformando em estatísticas, e estas em informações, do concreto para o abstrato, do ostensivo 
para o não-ostensivo, e é aqui que os materiais concretos manipuláveis podem ser um excelente apoio, como advogam Cazorla, Henriques e Santana (2020). Neste trabalho, utilizamos o cubo estatístico como um material potencialmente útil na representação e compreensão da transformação dos dados em estatísticas (tabelas, gráficos e MTC) e visualização de sua distribuição.

Ainda na perspectiva de dar sentido aos dados, Chick (2004) afirma a importância de trabalhar com dados multivariados, pois a riqueza de um ambiente motivador de conjecturas é potencializada quando colhemos dados de duas ou mais variáveis, e assim as crianças podem estabelecer paralelos, contrastes, comparações etc.

Para descrever as MTC, recorremos à Teoria do Campos Conceituais (TCC) proposta por Vergnaud (1982, 1984, 1987, 1990a, 1996), para quem um conceito é constituído pelo tripé (S, I, R), no qual as Situações (S) dão sentido ao conceito; os Invariantes (I) ou propriedades e as Representações simbólicas $(R)$ que são utilizadas para representá-lo. Desse modo, neste trabalho apresentamos a sequência de ensino a partir desse tripé e do que já foi investigado acerca do campo conceitual das MTC.

Com esses pressupostos, construímos uma sequência de ensino, envolvendo as MTC, ancorada na TCC e pautada no ciclo investigativo, utilizando o cubo estatístico para representar os dados brutos. Assim, nosso objetivo é analisar as potencialidades e limitações, do ponto de vista teórico, dessa sequência de ensino.

Este artigo está composto de cinco seções, além desta introdução; na segunda seção apresentamos uma breve revisão de trabalhos envolvendo as MTC; na terceira, o referencial teórico, focando a TCC para as MTC, o ciclo investigativo e o uso do material concreto manipulável, que dão suporte à construção da sequência de ensino; na quarta seção, apresentamos a sequência construída à luz dessas teorias; e, na quinta seção, apresentamos nossas conclusões e tecemos nossas considerações finais.

\section{O que já foi investigado sobre as MTC?}

A Estatística, mais do que ciência, é a arte de transformar os dados brutos em estatísticas (tabelas, gráficos e medidas resumo), e estas em informações que auxiliarão os indivíduos nas tomadas de decisões, a partir das evidências empíricas resultantes da análise de dados.

Esse potencial se deve ao fato de que os dados brutos - matéria prima da Estatística vêm dos mais diversos fenômenos/problemas da natureza e da sociedade, o que implica ter conhecimento do contexto do qual os dados foram extraídos. Além disso, as informações 
estatísticas dependem de como os dados foram gerados, isto porque, cada vez mais, as informações estatísticas têm sido utilizadas em narrativas que visam levar o cidadão à tomada de decisões, muitas vezes contrárias ao seu bem-estar, como vivenciamos nestes tempos de pandemia. Nesse sentido, estamos cientes de que devemos ensinar Estatística na perspectiva do desenvolvimento do raciocínio inferencial informal (MAKAR; RUBIN, 2009), visando a promoção do pensamento estatístico (WILD; PFANNKUCH, 1999).

Muito já foi investigado a respeito das MTC, todavia, dentre os trabalhos mais abrangentes temos os trabalhos do Grupo da Universidade de Granada, Espanha, liderado pela professora Carmen Batanero, sob o marco teórico do Enfoque Ontossemiótico. Por exemplo, Cobo e Batanero (2000) analisaram o conceito de mediana, apresentando quatro definições e situações para seu cálculo. Para as autoras, o cálculo da mediana depende de como os dados são apresentados (brutos ou agrupados) e apresentam as propriedades da mediana.

Posteriormente, Cobo (2003), na sua tese de doutorado, apresentou os significados das medidas de posição central para os estudantes de Ensino Médio, analisando os tipos de problemas, as representações, os procedimentos de cálculo, as definições, as propriedades e as argumentações relacionados com esses objetos, tanto em sua faceta institucional como pessoal. A autora realizou uma análise epistêmica de livros didáticos utilizados no ensino superior visando mapear o significado institucional, analisou o currículo e livros do Ensino Médio. Nessa mesma linha, Mayén, Cobo, Batanero e Balderas (2007) investigaram como estudantes mexicanos se comportaram ao resolver nove problemas envolvendo as MTC, esmiuçando definições, propriedades, campos de problemas, algoritmos e procedimentos.

Já Andrade (2013), na sua tese de doutorado, fez um estudo comparativo sobre as MTC no Brasil e na França, apoiado na Teoria Antropológica do Didático e na TCC. Ainda, fez uma proposta para o saber científico e uma análise da transposição didática dos programas e dos livros didáticos em ambos países. Como resultado, o pesquisador apontou limitações entre os programas e livros selecionados, constatando que as dificuldades encontradas estão relacionadas à forma como esses conhecimentos são transpostos nos programas e livros didáticos.

Figueiredo (2017), na sua dissertação de mestrado, realizou uma revisão de como a mediana é apresentada e calculada nos manuais escolares do $7^{\circ}$ e $8^{\circ}$ ano e nas Metas Curriculares de Matemática em Portugal.

Cazorla, Santana e Utsumi (2019) apresentam uma primeira aproximação do campo conceitual da média aritmética, ancorada na TCC, restrita ao campo empírico, explicitando a 
rede de conceitos, operações e propriedades que formam os Invariantes (I); as Representações (R) (verbal, numérica, algébrica, gráfica e pictórica), bem como as Situações (S) que dão sentidos diferenciados ao conceito. As autoras distinguem três classes de média: a simples, a agregada e a ponderada (a genuína; a ponderada pela frequência - valores pontuais e marca de classe; e a média geral a partir de médias parciais).

Com estes resultados em mente, a seguir apresentamos o referencial teórico que deu sustentação à construção da nossa sequência de ensino.

\section{Marco teórico}

A Teoria dos Campos Conceituais (TCC) parte do princípio de que o processo do ensino da Matemática costuma ter lugar numa certa sociedade, em uma dada instituição, e numa certa sala de aula. Isto significa que, embora os conteúdos matemáticos tenham características universais, o seu ensino se dá de diferentes formas e níveis. Isto porque esse ensino tem relação direta com a cultura e o avanço tecnológico de cada sociedade, com a posição psico-pedagógica da instituição de ensino e, ainda, com a formação (de conteúdo específico e pedagógico) do professor. Esses fatores levam a objetivos e pontos de chegadas distintos.

Sob a égide dessa posição epistemológica, Vergnaud (1990b, p. 3) levanta as seguintes questões:

Qual é a natureza e a função de um novo conceito, um novo procedimento, um novo tipo de raciocínio, uma nova representação? Mais precisamente, qual é a relação existente entre as novas competências e concepções matemáticas e os problemas práticos e teóricos que as tornam valiosas e significativas?

Vergnaud (1990b) considera que esse tipo de pergunta é essencial para ajudar os professores a escolher as situações a serem trabalhadas com seus alunos. Para ele, a identificação dos conceitos envolvidos numa dada situação-problema e das propriedades relevantes para a sua resolução, usando certas representações, é crucial para a análise cognitiva sobre o entendimento dos comportamentos assumidos pelos estudantes durante sua resolução.

A partir dessas considerações iniciais, podemos afirmar que a Teoria dos Campos Conceituais é uma teoria psicológica, de cunho cognitivista, construída no âmbito da Educação Matemática e tendo por foco a sala de aula e o processo de formação e desenvolvimento de conceitos matemáticos pelos estudantes. 
Desse ponto de vista, Vergnaud $(1982,1984,1987)$ propõe um tripé composto por três elementos inter-relacionados, que juntos sustentam a formação do conceito $S, I, R^{1}$ : o conjunto de situações (S), no qual se encontra inserido o objeto matemático e que dá significado ao conceito em questão; o conjunto de invariantes (I), que caracteriza a variedade de competências dos estudantes e que faz parte das propriedades do conceito; e o conjunto das Representações Simbólicas (R), por meio da qual os invariantes (propriedades, procedimentos, teoremas-emação) e as situações são representados.

Vergnaud (1984, p. 19) faz uma comparação entre esse tripé e os elementos da semiótica ao afirmar que "eu chamaria o S de referente, o I de significado, e o R de significante". Nessa direção, o referente (conjunto de Situações) é o mundo real e emerge da experiência individual da pessoa. O significado (conjunto de invariantes) está no cerne da teoria da representação, uma vez que é neste nível que os "invariantes são reconhecidos, as inferências tiradas, as ações generalizadas e as predições feitas" (VERGNAUD, 1987, p. 229). Por fim, o significante (conjunto de representações simbólicas) consiste de diferentes sistemas simbólicos "que são diferentemente organizados: a sintax da álgebra é diferente da sintax dos gráficos, dos diagramas e das tabelas" (VERGNAUD, 1987, p. 229).

A partir desse ponto de vista, a Representação Simbólica R é epistemologicamente vista por Vergnaud como surgindo a partir da interação entre o Conjunto de Situações S (referente) e o conjunto de invariantes I (significado), obtendo assim um significante para o conceito. Ao longo deste artigo faremos considerações nas quais esse tripé estará como suporte delas.

Com este marco teórico, analisamos o tripé para as MTC.

As MTC resumem os dados a um ou a poucos números e indicam o local onde os dados tendem a se concentrar ou o centro dos dados. As MTC a serem trabalhadas na Educação Básica são a Moda, Mediana e Média e envolvem uma rede de conceitos, sendo que as situações (S) dependem da natureza da variável e de como os dados estão disponibilizados, isto é, se são qualitativas ou quantitativas e se os dados estão em sua forma original (dados brutos) ou já estão agrupados; os invariantes são formados pelos conceitos fundamentais e as propriedades das MTC, e as representações dizem respeito a como os dados e as MTC são aprendidos e comunicados, como descrevemos neste trabalho.

\footnotetext{
${ }^{1}$ Inicialmente, o símbolo usado para o conjunto da Representação Simbólica no triângulo era “ $\boldsymbol{J}$ ", feito à mão por Vergnaud. Ele foi usado em todos os textos da década de 80, mas como ficava muito difícil escrevê-lo, os pesquisadores que se referiam a esse tripé passaram a utilizar o " $\mathrm{R}$ ” maiúsculo em seu lugar.
} 
Segundo a BNCC (BRASIL, 2018), os conceitos a serem ensinados na Educação Básica são: população, amostra, variável, dados, tabelas estatísticas e tabelas de frequência (TDF), gráficos estatísticos (pictogramas, barras/colunas, setores, linhas, histograma, ramos e folhas e diagrama da caixa ou box-plot), as MTC (Média, Mediana e Moda) e as medidas de dispersão (amplitude e desvio padrão). Como mencionamos, a BNCC não elencou as MTC como objeto de conhecimento a ser trabalhado nos anos iniciais, mas advogamos seu ensino de forma intuitiva e lúdica, por isso, vamos restringir o escopo das MTC para os dados brutos, isto é, não abordaremos as MTC para dados agrupados. A seguir conceituamos brevemente as três MTC.

A Moda (Mo) é a única MTC que existe para todas as variáveis. Sua definição é bastante intuitiva. No caso de uma variável qualitativa, a moda é a categoria que ocorre com maior frequência; no caso de uma variável discreta que toma poucos valores (valores pontuais), a moda é o valor que ocorre com maior frequência e, se a variável for contínua ou discreta que toma muitos valores, a Moda pode não existir (ou não ter sentido). Para encontrá-la, será necessário construir a TDF em intervalos de classe, a qual é "dada pela densidade de frequência máxima" (ANDRADE, 2013, p. 127) e, nesse caso, uma aproximação será o ponto médio do intervalo de maior frequência, como exemplificamos nesta sequência de ensino.

A Mediana (Md) divide a quantidade de dados (n) em duas partes iguais, sendo que metade dos dados toma valores menores ou iguais a ela, enquanto a outra metade, valores maiores ou iguais. Segundo Cobo e Batanero (2000, p. 3),

Se ordenarmos todos os valores de uma variável estatística, do menor ao maior, o valor da variável é chamado de mediana de forma que haja tantos dados com valores da variável maiores ou iguais quanto menores ou iguais a ele (tradução dos autores).

Se os dados estão na sua forma bruta, será preciso ordená-los. Para tal, é desejável organizar os dados com sua respectiva posição ou representar em um diagrama de pontos. Neste caso, basta examinar se a quantidade de dados (n) é impar ou par e determinar a(s) posição(ões) central(ais):

a) Se $\mathrm{n}$ for ímpar, então a posição central será $(\mathrm{n}+1) / 2$ e a mediana tomará $\mathrm{o}$ valor que ocupa essa posição: $\mathrm{Md}=\mathrm{X}_{((\mathrm{n}+1) / 2)}$;

b) Se $n$ for par, então a posição central estará entre as posições (n/2) e o subsequente $(\mathrm{n} / 2)+1$ e a mediana será a média desses dois valores: $\mathrm{Md}=$ $\left(\mathrm{X}_{(\mathrm{n} / 2)}+\mathrm{X}_{(\mathrm{n} / 2)+1}\right) / 2$.

A Média (M) é definida como a razão entre a soma dos valores da variável e a quantidade de dados, cujo algoritmo depende da natureza dos dados, que pode ser simples, 
agregada ou agrupada, como destacam Cazorla, Santana e Utsumi (2019). Neste trabalho só trabalharemos a média aritmética simples, que a denominaremos de Média.

A seguir apresentamos o tripé $(\mathrm{S}, \mathrm{R}, \mathrm{I})$ que dá sustentação às MTC.

As Representações (R). Neste particular, chamamos a atenção para não confundir representação dos dados e representação das MTC. As MTC tomam um único valor (Média e Mediana), e apenas a Moda pode tomar mais de um valor ou categoria. Assim, os dados podem estar em sua forma bruta (listas, rol, banco ou planilhas de dados), de forma numérica ou verbal (na língua materna), no seu formato numérico disposto em tabelas estatísticas ou em tabelas de distribuição de Frequência (TDF) ou, ainda, em gráficos estatísticos, desde que preservem os dados brutos, como os gráficos de barras, hastes/bastão, de pontos (dot-plot), ramos e folhas. É importante observar que no histograma só se pode encontrar as MTC por aproximação; no boxplot isso não é mais possível. Já as MTC só podem ser representadas no seu formato numérico, verbal, icônico (o triângulo tem sido utilizado como o "fiel da balança" para representar a Média) ou gráfico, no caso de uma linha reta, como apresentam Cazorla, Santana e Utsumi (2019).

As Situações (S) dependem da natureza dos dados e de como eles estão dispostos. Como estamos propondo a sequência para os anos iniciais, abordamos apenas três situações que envolvem os dados brutos, a primeira para variáveis qualitativas $(\boldsymbol{S} 1)$, a segunda para variáveis discretas que tomam poucos valores $(\boldsymbol{S} 2)$ e, a terceira, para variáveis contínuas $(\boldsymbol{S} 3)$, conforme Quadro 1.

Quadro 1 - Situações e Invariantes das MTC a partir de dados brutos

\begin{tabular}{|c|c|c|c|c|c|c|}
\hline \multirow{2}{*}{\multicolumn{3}{|c|}{ Natureza da variável }} & \multirow{2}{*}{$\begin{array}{l}\text { Situa- } \\
\text { ções }\end{array}$} & \multicolumn{3}{|c|}{ Invariantes } \\
\hline & & & & Moda & Mediana & Média \\
\hline \multirow{2}{*}{ : } & & Nominal & \multirow{2}{*}{$\mathrm{S} 1$} & \multirow{2}{*}{$\begin{array}{l}\text { Categoria } \\
\text { mais } \\
\text { frequente }\end{array}$} & Não existe & Não existe \\
\hline & \multicolumn{2}{|r|}{ Ordinal } & & & Existe sob certas condições* & Não existe \\
\hline \multirow{3}{*}{ 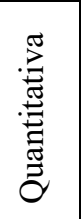 } & $\underset{0}{0}$ & $\begin{array}{l}\text { Poucos } \\
\text { valores }\end{array}$ & $\mathrm{S} 2$ & $\begin{array}{l}\text { Valor mais } \\
\text { frequente }\end{array}$ & $\begin{array}{l}\text { Valor que ocupa a posição } \\
\text { central }\end{array}$ & $\begin{array}{l}\text { Soma dos valores da } \\
\text { variável dividida pela }\end{array}$ \\
\hline & $\stackrel{0}{\mathscr{n}}$ & $\begin{array}{l}\text { Muitos } \\
\text { valores }\end{array}$ & \multirow{2}{*}{ S3 } & \multirow{2}{*}{$\begin{array}{l}\text { Pode não ter } \\
\text { sentido** }\end{array}$} & n ímpar: $\mathrm{Md}=x_{(\mathrm{n}+1) / 2}$ & $\begin{array}{l}\text { quantidade de dados: } \\
\qquad M=\frac{\sum_{i=1}^{n} x_{i}}{}\end{array}$ \\
\hline & \multicolumn{2}{|c|}{ Contínua } & & & $\mathrm{n}$ par: $\mathrm{Md}=\left\{x_{\left.(\mathrm{n} / 2)+x_{((\mathrm{n} / 2)+1)}\right\} / 2}\right.$ & $n$ \\
\hline
\end{tabular}

* Indeterminado para $\mathrm{n}$ par e as posições centrais ficarem em classes diferentes.

**Será explicitado na segunda situação da sequência de ensino.

Fonte: construção dos autores 
Situação 1 (S1). Nesta situação colocamos todas as variáveis qualitativas nominais (gênero, mascote favorita), ordinais (gosta da merenda) e sequenciais ${ }^{2}$ (mês de aniversário). Todas estas variáveis possuem apenas a Moda e o seu tratamento e representação é similar com a TDF em categorias e gráficos de barras/circular/pictogramas. No Quadro 1 colocamos a Mediana para variáveis ordinais (ANDRADE, 2013; MAYÉN e colaboradores, 2017). Todavia, caso o número de dados seja par e as posições centrais fiquem em classes diferentes, essa fica indeterminada, o que pode trazer conflitos didáticos ao ser abordada nos anos iniciais. Por isso, não recomendamos seu uso neste nível de ensino e não o abordamos neste trabalho.

Situação 2 (S2). Nesta situação colocamos as variáveis discretas (resultado de contagem) que tomam poucos valores (p.e. quantidade de letras do primeiro nome, quantidade de irmãos) e que possuem as três MTC. Seu tratamento e representação, na Educação Básica, têm sido como uma variável ordinal, utilizando a TDF em valores pontuais e gráficos de barras/colunas, diagrama de ramos e folhas. Todavia advogamos a utilização do diagrama de pontos e de hastes/bastão, apesar de a BNCC não ter elencado como objetos de conhecimento.

Situação 3 (S3). Nesta situação colocamos as variáveis discretas que tomam muitos valores (p.e. quantidade de alunos por turma) e as variáveis contínuas (resultantes de mensuração), como a altura. Seu tratamento e representação incluem a construção de TDF em intervalos de classe e o histograma, diagrama de ramos e folhas e da caixa (box-plot). Aqui também advogamos a utilização do diagrama de pontos. Como este tipo de variável toma muitos valores, pode ser que a Moda não tenha sentido, fazendo-se necessário calcular por aproximação, utilizando a densidade (ANDRADE, 2013), como mostramos na sequência de ensino.

Observamos que a Mediana e a Média têm o mesmo procedimento para sua obtenção na S2 e S3, mas existem nuances que explicitamos na sequência de ensino.

Os Invariantes (I) são formados pela rede de conceitos que dão sustentação ao campo conceitual, bem como as propriedades das MTC que unificam e distinguem as situações que lhe dão sustentação, que sintetizamos no Quadro 2.

\footnotetext{
${ }^{2}$ Segundo Cazorla, Utsumi e Monteiro (2021), a variável tempo é uma variável sequencial, que além de ordinal mantém intervalos uniformes entre as categorias (meses, anos etc.), diferente de uma ordinal, cujas categorias mantêm apenas a ordem.
} 
Quadro 2 - As propriedades (Invariantes) das MTC restritas ao seu ensino nos anos iniciais

\begin{tabular}{|c|c|c|c|}
\hline (a) Propriedades (Invariantes) & Média & Mediana & Moda \\
\hline 1. Está localizada entre os valores extremos $\left(\mathrm{X}_{\min } \leq \mathrm{MTC} \leq \mathrm{X}_{\max }\right)$ & Sim & Sim & Sim \\
\hline $\begin{array}{l}\text { 2. É influenciada por cada um e por todos os valores (ou é influenciada } \\
\text { pelos valores extremos) }\end{array}$ & Sim & Não & Não \\
\hline 3. Coincide com um dos valores que a compõem & Às vezes & Às vezes & Sim \\
\hline $\begin{array}{l}\text { 4. Pode ser um número que não tem um correspondente na realidade } \\
\text { física }\end{array}$ & Às vezes & Às vezes & Não \\
\hline $\begin{array}{l}\text { 5. Seu cálculo leva em consideração todos os valores, inclusive os } \\
\text { nulos e os negativos }\end{array}$ & Sim & Não & Não \\
\hline 6. É um valor representativo dos dados a partir do qual foi calculada & Sim & Sim & Sim \\
\hline 7. É o ponto de equilíbrio (centro de gravidade) & Sim & Não & Não \\
\hline 8. Está mais próxima de todos os valores & Sim & Não & Não \\
\hline 9. $\quad$ Pode ser calculada a partir de resultados parciais & Sim & Não & Não \\
\hline $\begin{array}{l}\text { 10. A soma dos valores pode ser obtida multiplicando a MTC pelo } \\
\text { número de dados }\end{array}$ & $\operatorname{Sim}$ & Não & Não \\
\hline
\end{tabular}

Fonte: Magina, Lautert e Cazorla (in press).

Além da TCC, a sequência de ensino foi delineada percorrendo as fases do ciclo investigativo (PPDAC) proposto por Wild e Pfannkuch (1999), que envolve o estudante em todo o processo de investigação, desde a formulação do problema $(\mathrm{P})$, planejamento $(\mathrm{P})$, coleta de dados (D), análise dos dados (A) até as conclusões (C). Apresentamos essas fases exemplificadas na sequência de ensino.

Por fim, na sequência de ensino, utilizamos o cubo estatístico como um material concreto manipulável (ostensivo) que auxilia a compreensão da transformação dos dados brutos em estatísticas (não ostensivos), como proposto por Cazorla, Henriques e Santana (2020), que permite registrar nas suas fases as variáveis estatísticas que serão trabalhadas na investigação com as crianças. Trata-se do Referente (a Situação) com o qual as crianças irão interagir (representar seus dados no cubo, elas o empilharão em classes, em valores pontuais etc.). Isso é, o cubo representa o seu dado e permite que a criança acompanhe a transformação dos dados (o conjunto de invariantes) nas MTC (conjunto de Representações simbólicas, o significante, fruto da interação Referente-Significado), como veremos a seguir.

\section{A sequência de ensino}

A sequência de ensino foi delineada para trabalhar as MTC nos anos iniciais do Ensino Fundamental. Isso implica que devemos recolher dados qualitativos, discretos e contínuos, acessíveis e na ordem de grandeza adequada para essa faixa etária e possíveis de serem representados no cubo estatístico.

Na fase da formulação do Problema (P), o professor precisa escolher uma pergunta norteadora. Nesta sequência, escolhemos a seguinte: “As meninas têm nomes mais curtos do 
que os meninos?". Aqui já temos duas variáveis: a quantidade de letras do primeiro nome, que é discreta (resultado de contagem) e toma poucos valores; e o gênero, que é qualitativa nominal.

Na fase do Planejamento $(\boldsymbol{P})$, o professor precisa organizar a condução da pesquisa. Neste exemplo, ele possui a lista de chamada e pode verificar a melhor estratégia para conduzir a pesquisa e decidir se trabalhará apenas com o primeiro nome ou com os dois nomes. Isso dependerá do ano de escolarização das crianças, dos conhecimentos prévios e do domínio das operações fundamentais, contagem, ordenamento etc. Outro aspecto a ser levado em consideração é o tamanho da turma, pois tratar 20 ou mais dados é trabalhoso para crianças pequenas.

Como a ideia é trabalhar no contexto multivariado e queremos analisar os diversos tipos de variáveis, neste trabalho elencamos outras variáveis (Quadro 3) que apresentam peculiaridades tanto nos dados quanto no cálculo das MTC.

Nos anos iniciais, as variáveis qualitativas são bastante trabalhadas. Por essa razão, não abordaremos neste artigo. A Variável "Mês de aniversário" é bastante interessante, pois o mês poderia ser representado com números e as crianças podem ser tentadas a calcular a média, o que não tem sentido.

Quadro 3 - Exemplo de variáveis que podem ser trabalhadas as MTC nos anos iniciais

\begin{tabular}{|l|c|l|l|l|}
\hline Variável & Situação & Tipo* & Possíveis valores & MTC \\
\hline Gênero & S1 & Qualitativa nominal & F: Fem; M: Mas. & Mo \\
\hline Mascote favorita & S1 & Qualitativa nominal & $\begin{array}{l}\text { C: Cachorro; G: Gato; H: } \\
\text { Hamster; P: Peixe }\end{array}$ & Mo \\
\hline Gosta da merenda & S1 & Qualitativa ordinal & $\begin{array}{l}\text { N: Não; I: Indiferente; G: } \\
\text { Gosto }\end{array}$ & Mo \\
\hline Mês de aniversário & S1 & $\begin{array}{l}\text { Contínua discretizada } \\
\text { (sequencial) }\end{array}$ & $\begin{array}{l}\text { janeiro, fevereiro, ... } \\
\text { dezembro }\end{array}$ & Mo \\
\hline $\begin{array}{l}\text { Quantidade de letras } \\
\text { do primeiro nome }\end{array}$ & S2 & Quantitativa discreta & $3,4,5,6,7,8,9$ & Mo, Md, M \\
\hline Quantidade de irmãos & S2 & Quantitativa discreta & $0,1,2,3,4,5$ & Mo, Md, M \\
\hline Idade & S2 & Contínua discretizada & $6,7,8,9,10,11,12$ (anos) & Mo, Md, M \\
\hline No do calçado & S2 & Contínua discretizada & $32,33,34,35,35,37$ & Mo, Md, M \\
\hline Altura & S3 & Contínua discretizada & De 140 a $170 \mathrm{~cm}$ & Mo*, Md, M \\
\hline
\end{tabular}

*discretizada significa tomada em valores inteiros

Fonte: construção dos autores.

As variáveis "Quantidade de letras do primeiro nome" e "Quantidade de irmãos" são discretas que tomam poucos valores (em geral de um dígito). Todavia a variável quantidade de irmãos pode tomar valor zero e crianças pequenas acreditam que zero não é dado e não levam em consideração no cálculo da Média, logo é uma boa oportunidade para trabalhar essa variável. O número do calçado também é uma variável discreta que toma poucos valores, porém com 
dois dígitos, com valores entre 30 a 40 (dependendo do ano escolar). Já a idade e a altura são variáveis contínuas, mas, em geral, são expressas em números inteiros (discretizadas). A idade, a depender do ano escolar e da turma, pode tomar pouquíssimos valores, por exemplo, na turma do $5^{\circ}$ ano, a idade variou entre 9 e 10 anos. Já a altura pode tomar mais valores, o que demandará maiores cuidados para seu ensino, como veremos na sequência desenvolvida.

Para a escolha das variáveis a serem trabalhadas, deve-se levar em consideração a quantidade de cálculos envolvidos para evitar que a atividade se torne enfadonha e cansativa. Todavia existem trabalhos mostrando a forma lúdica para trabalhar, assim como estratégias de trabalhar em grupos e de forma coletiva.

Outro aspecto a ser levado em consideração na escolha das variáveis é o caráter inferencial da investigação, para o qual é aconselhável analisar uma variável por outra, como o gênero, local de residência (urbana, rural) etc. Nesse sentido, o professor deve conduzir o processo fazendo perguntas que estimulem a curiosidade, a conjectura de hipóteses e a argumentação. Por exemplo, não há nenhuma evidência de que a quantidade de irmãos, mês de aniversário ou idade sejam diferenciados por gênero; mas o tamanho do calçado e a altura das crianças podem estar relacionados ao gênero. Já nas variáveis qualitativas, como a mascote favorita ou gosta da merenda, pode ser interessante examinar se as meninas apresentam um perfil diferenciado dos meninos, trabalhando com tabelas de dupla entrada.

Desse modo, o professor pode se inspirar nessas variáveis para trabalhar outras variáveis de acordo com o contexto da escola e das crianças de sua turma. O professor não precisa trabalhar com todas estas variáveis, mas ele deve escolher no mínimo duas, a fim de explorar o caráter inferencial da Estatística. Para escolher quais variáveis trabalhar, o professor deve analisar o potencial de cada uma delas para, assim, ampliar o campo conceitual das MTC.

Uma vez fixadas as variáveis, o professor precisa decidir como as crianças vão registrar os dados. Para isso, pode confeccionar fichas, como a da Figura 1a, utilizar o cubo estatístico (Figura 1b), no qual as faces servem para representar seis variáveis e a cor do cubo para representar uma variável qualitativa, como o gênero, ou ainda trabalhar com papeizinhos padronizados, como sugerem Cazorla, Henriques e Santana (2020). Nesta sequência utilizamos o cubo estatístico para representar sete variáveis, sendo o gênero representado pela cor (rosa para as meninas e verde para os meninos). A escolha das cores se deu pela disponibilidade de material. 
Nesta sequência de ensino apresentamos dois exemplos, um do tipo $\boldsymbol{S} \mathbf{2}$ (discreta que toma poucos valores), analisando a quantidade de letras do primeiro nome, e outra do tipo $\boldsymbol{S} 3$ (contínua), analisando a altura, que denominaremos $\boldsymbol{S} 2$ e $\boldsymbol{S} 3$.

Figura 1 - Instrumentos para a coleta de dados

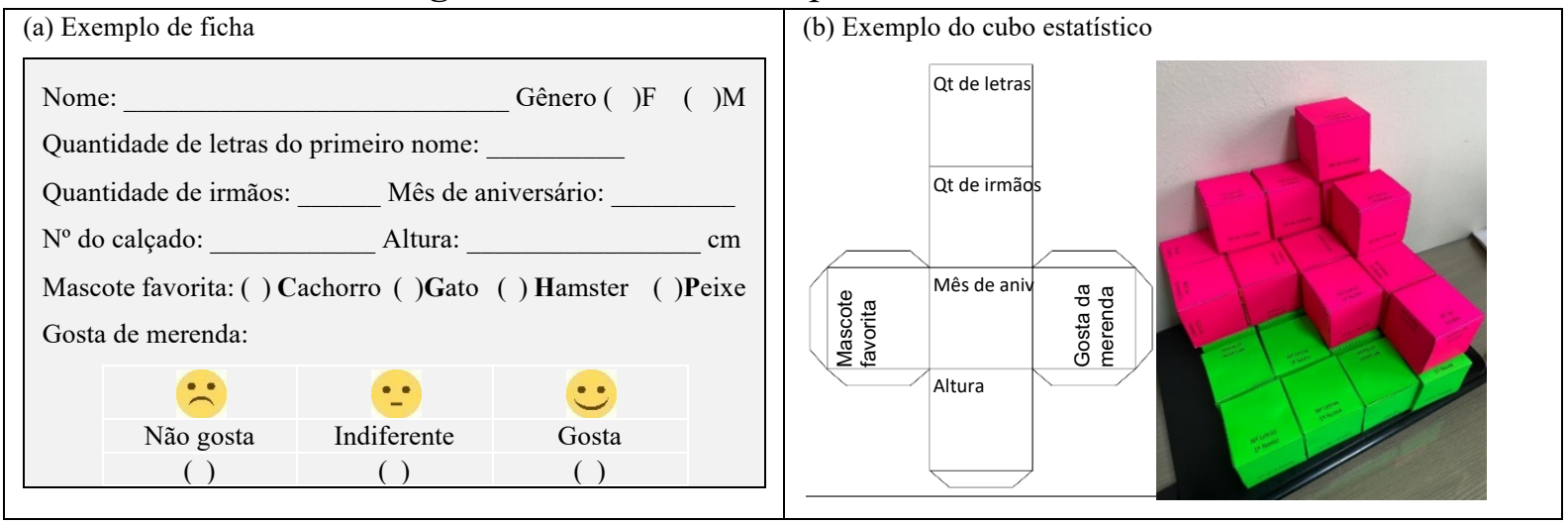

Fonte: construção dos autores.

Na fase de Dados (D), o professor entregará a ficha ou o cubo e solicitará que as crianças preencham com seus dados. É desejável construir uma planilha em papel madeira e fixar na parede, possibilitando às crianças preencher seus dados na linha correspondente aos seus nomes. Assim o banco de dados fica permanente, permitindo trabalhar em momentos diferenciados. No Quadro 4 apresentamos um banco de dados fíctício, adaptado dos dados de uma turma de $5^{\circ}$ ano, contendo apenas as variáveis que serão aqui trabalhadas. Os dados estão organizados por gênero e em ordem alfabética do primeiro nome das crianças para facilitar o seu tratamento.

Quadro 4 - Banco de dados de uma turma do $5^{\circ}$ ano (idades entre 9 e 10 anos)

\begin{tabular}{|c|l|l|c|c|c|}
\hline Código & Nome & $1^{\circ}$ nome & Gênero & Qtde. de letras (S2) & Altura (cm) S3 \\
\hline 1 & Ana Beatriz & Ana & F & 3 & 155 \\
\hline 2 & Ana Clara & Ana & F & 3 & 156 \\
\hline 3 & Carla & Carla & F & 5 & 165 \\
\hline 4 & Clara & Clara & F & 5 & 157 \\
\hline 5 & Elizabete & Elizabete & F & 9 & 162 \\
\hline 6 & Júlia & Júlia & F & 5 & 164 \\
\hline 7 & Luiza & Luiza & F & 5 & 158 \\
\hline 8 & Maria Eduarda & Maria & F & 5 & 145 \\
\hline 9 & Marta & Marta & F & 5 & 150 \\
\hline 1 & Arthur & Arthur & M & 6 & 155 \\
\hline 2 & Caio & Caio & M & 4 & 168 \\
\hline 3 & Carlos Augusto & Carlos & M & 6 & 169 \\
\hline 4 & Diogo & Diogo & M & 5 & 162 \\
\hline 5 & Eduardo & Eduardo & M & 7 & 164 \\
\hline 6 & Enzo Dimitri & Enzo & M & 4 & 159 \\
\hline 7 & Fernando & Fernando & M & 8 & 161 \\
\hline 8 & Gustavo & Gustavo & M & 7 & 160 \\
\hline
\end{tabular}




\begin{tabular}{|c|l|l|l|l|l|}
9 & João Gabriel & João & M & 4 & 158 \\
\hline 11 & Leo & Leo & M & 3 & 156 \\
\hline 10 & Luiz & Luiz & M & 4 & 156 \\
\hline 12 & Miguel & Miguel & M & 6 & 158 \\
\hline 13 & Thiago & Thiago & M & 6 & 155 \\
\hline 14 & Vicente & Vicente & M & 7 & 157 \\
\hline
\end{tabular}

Fonte: construção dos autores.

S2: A fase da Análise (A) deve ser iniciada com o professor fazendo perguntas do tipo: como podemos verificar se o nome das meninas é mais curto do que o nome dos meninos? Posteriormente, é importante deixar as crianças externarem suas ideias. Provavelmente, a ideia de comparar surgirá naturalmente e assim o professor mostrará às crianças que será necessário organizar os dados.

A primeira estratégia será a construção da TDF. Para isso, o professor pode solicitar que as crianças cujos nomes têm três letras levantem a mão, mostrando seus cubos, contando junto com elas quantas são meninas, quantos são meninos e registrar no quadro; em seguida, solicitar às crianças cujos nomes têm quatro letras, e assim por diante. Assim o professor estará construindo a TDF (Figura 2a), explicando para as crianças o significado de seus componentes.

Outra estratégia é solicitar que as crianças empilhem os cubos em cima da mesa, ordenados segundo a quantidade de letras (Figura 2b). Também, pode-se distribuir papeizinhos padronizados, nos quais as crianças podem escrever seus nomes e colar no quadro (Figura 2c). A seguir podemos construir o gráfico de barras lado a lado (Figura 2d) e/ou empilhado (Figura e). Também, pode-se recorrer aos pictogramas. Isso fica a cargo da criatividade do professor. Ainda, estamos sugerindo a construção do diagrama de pontos (ver Figura 5).

Figura 2 - Possibilidades de representação dos dados da $\boldsymbol{S} 2$ (discreta que toma poucos valores)

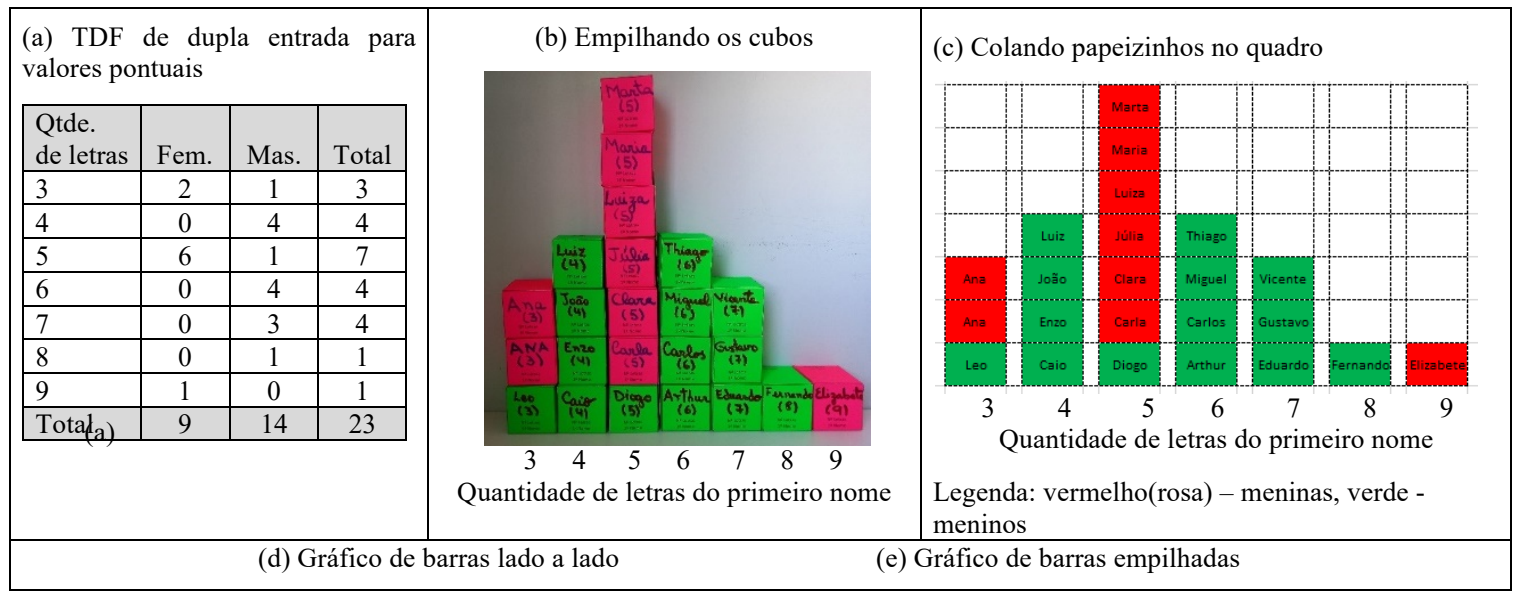




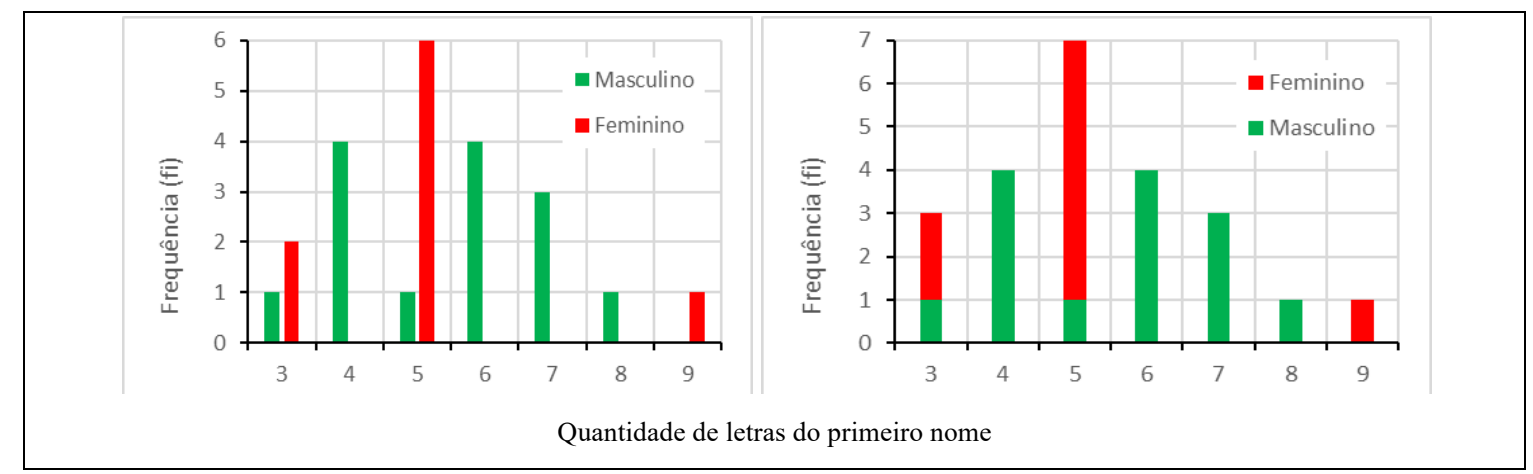

Fonte: construção dos autores.

Com essas representações, o professor retoma a pergunta de pesquisa: o nome das meninas é mais curto do que o nome dos meninos? Para isso, as crianças devem examinar a TDF, os cubos empilhados ou os gráficos construídos. Provavelmente algumas crianças dirão que não, porque o nome da Elizabete tem nove (9) letras (o nome mais comprido), ou que sim, porque têm duas meninas cujos nomes têm três letras. Diversos autores mostram que a tendência inicial das crianças é olhar os valores máximo, mínimo. Outras crianças podem examinar a amplitude dos dados (de 3 a 9 para as meninas e de 2 a 8 para os meninos) ou os valores mais frequentes, que é a Moda, arguindo que a maioria das meninas (seis) tem nomes com cinco letras, enquanto que os meninos têm seus nomes entre quatro (quatro meninos) e seis letras (quatro meninos). Nessa discussão, o professor deve chamar a atenção das crianças para o fato de que são apenas nove meninas contra quatorze meninos. Então a comparação em termos absolutos fica comprometida. Caso a turma seja do $5^{\circ}$ ano, o professor pode recorrer à frequência relativa.

Até aqui as crianças já podem ter utilizado a Moda e, nesse caso, o professor pode formalizar esse conceito. Caso não, ele pode indicar as crianças para olhar os valores mais frequentes, examinando os valores na $\mathrm{TDF}$, procurando o maior valor na coluna referente às meninas, constatando que a Moda é de 5 letras; do mesmo modo, examinando na coluna referente aos meninos, constatando que há um empate entre 4 e 6 letras. Já a moda para a turma, sem distinguir o gênero, é cinco, muito pela influência do tamanho do nome das meninas.

De posse desses resultados, novamente o professor indaga à turma se já se pode responder à pergunta de pesquisa. A discussão pode ficar bastante rica, pois de um lado a maioria das meninas (6 de 9) tem nomes com 5 letras; já a maioria dos meninos tem nomes com 4 e 6 letras ( 8 de 14), o que fica indeterminado, indicando um empate.

A seguir, o professor pode informar às crianças que existem outras formas de comparar de forma mais resumida e apresentar a Mediana, de forma intuitiva. Para encontrar a Mediana, 
no caso das meninas, o professor pode solicitar a elas que se enfileirem (mostrando seus cubos) em ordem, de acordo com a quantidade de letras do seu primeiro nome. Como haverá vários empates, o professor pode solicitar que as meninas cujos nomes têm a mesma quantidade de letras se enfileirem em ordem alfabética, de acordo com a inicial do nome, esquematicamente, conforme Figura 3a. Como são nove meninas, um número ímpar de dados, então a mediana ocupa a $5^{\text {a }}$ posição $(n+1) / 2$. Neste exemplo, temos a posição da Júlia, logo a mediana será 5 letras. Aqui o professor pode solicitar às crianças que contem quantas meninas estão à esquerda de Júlia (4 meninas) e quantas à direita (4 meninas), constatando que "metade" dos dados toma valores menores ou iguais a 5 (letras), e a outra metade toma valores maiores ou iguais a 5 . Da mesma forma o professor procede com os meninos (Figura 3b); como são 14 meninos, número par de dados, então a Mediana estará ocupando as posições $7^{\mathrm{a}}$ (Arthur) e $8^{\mathrm{a}}$ (Carlos), e será a média dos valores que ocupam essas posições, isto é, igual a 6 . As crianças podem constatar que a mediana está entre Arthur e Carlos e que à esquerda têm sete meninos e à direita também 7 meninos. Neste caso, a Mediana separa o conjunto de dados "literalmente" em duas metades. De forma similar, pode proceder para encontrar a Mediana para a turma. Neste caso, $n=23$. Logo a posição será a $12^{\mathrm{a}}$ (Figura $3 \mathrm{c}$ ).

Neste exemplo, as crianças ficarão confusas, pois no caso das meninas, o número de letras do nome da Júlia pertence aos dois conjuntos, diferentemente do caso dos meninos. Além disso, no caso das meninas, seis das nove meninas têm nomes com 5 letras ao igual que Júlia, portanto, todas as cinco poderiam reclamar para si ser a posição da mediana, como fica muito claro no diagrama de pontos (Figura 5). Por essa razão, é importante trabalhar a ordenação e a organização dos dados em tabelas e gráficos, de preferência utilizando materiais concretos que auxiliem os estudantes a compreender essas nuances do conceito de mediana. Dessa forma, o professor pode formalizar de forma intuitiva este conceito.

Figura 3 - Encontrando a Mediana na $\boldsymbol{S 2}$ (discreta que toma poucos valores)

(a) Encontrando a Mediana para a quantidade de letras dos nomes das meninas

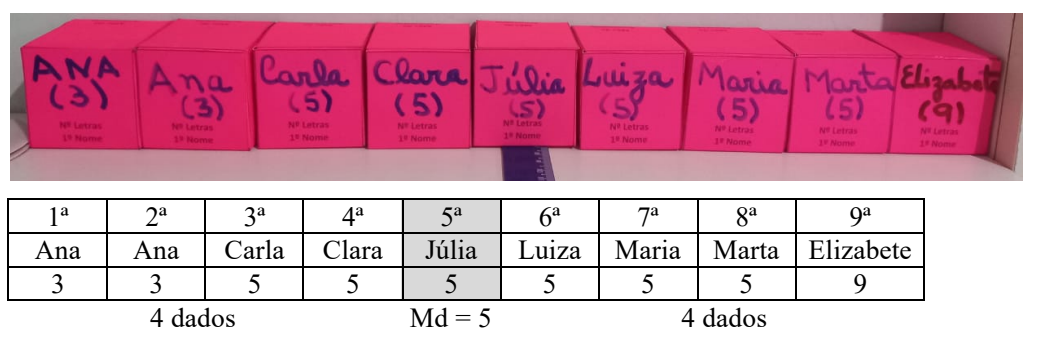

(b) Encontrando a Mediana para a quantidade de letras dos nomes dos meninos 


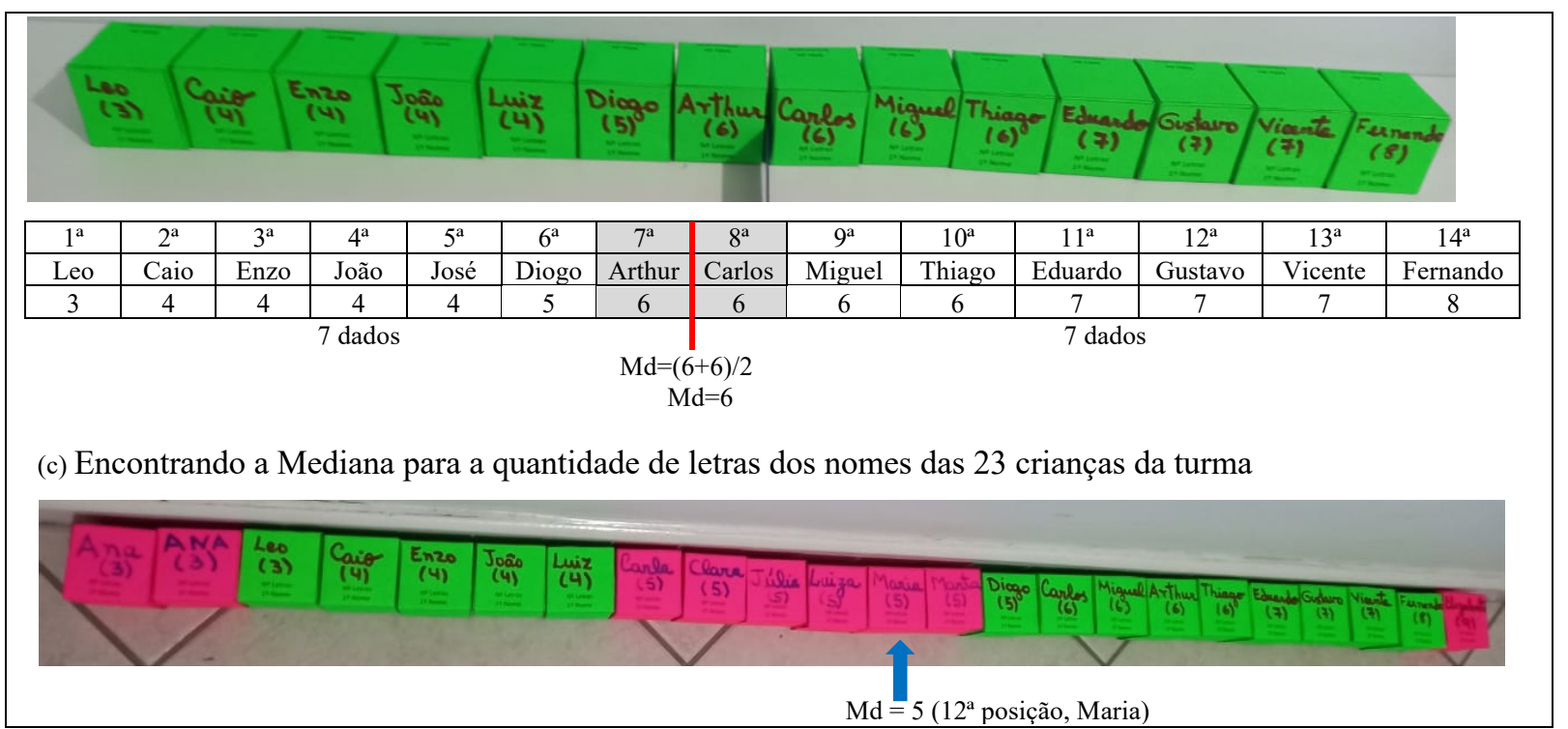

Fonte: construção dos autores.

Para apresentar a Média, o professor poderia perguntar: "quantas letras têm ao todo o nome das nove meninas? A resposta será 45. A seguir indagaria: se dividíssemos essa soma entre a quantidade de meninas (nove), o que resultaria? O que isso significaria? Dividir as 45 letras entre as 9 meninas significa "repartir todas as letras em partes iguais entre todas as meninas", que Cobo e Batanero (2000) denominam de um campo de problemas da média (Figura 4a). Do mesmo modo procedemos com os nomes dos meninos, que resulta em 5,5 (Figura 4b) letras, e de todas as crianças, que resulta 5,3 letras (Figura 4c).

Figura 4 - Encontrando a Média

(a) Encontrando a Média para a quantidade de letras dos nomes das meninas:

$$
M_{F}=\frac{3+3+5+5+5+5+5+5+9}{9}=\frac{45}{9}=5 \text { letras }
$$

(b) Encontrando a Média para a quantidade de letras dos nomes dos meninos:

$$
M_{M}=\frac{3+4+4+4+4+5+6+6+6+6+7+7+7+8}{14}=\frac{77}{14}=5,5 \text { letras }
$$

(c) Encontrando a Média para a quantidade de letras dos nomes das crianças

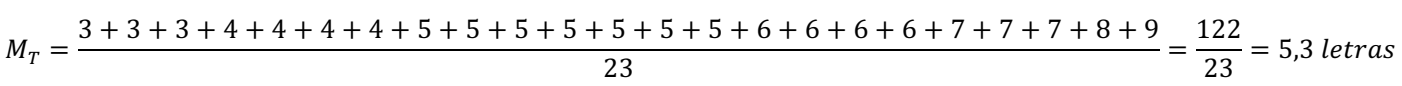

(d) Encontrando a média da turma utilizando sua propriedade:

$$
M_{T}=\frac{\text { Soma }(\text { meninas })+\text { Soma }(\text { meninos })}{n(\text { meninas })+n(\text { meninos })}=\frac{45+77}{9+14}=\frac{122}{23}=5,3 \text { letras }
$$

Fonte: construção dos autores.

Para calcular a média da turma (Figura 4d), o professor pode perguntar como podem encontrar a quantidade total de letras dos nomes de todas as crianças, conhecendo o total de letras dos nomes das meninas e dos meninos, indicando que bastaria somar os totais parciais. 
Ainda neste procedimento, o professor pode mostrar às crianças que não podemos calcular a média das médias parciais, pois o número de meninas e meninos é diferente.

De posse das médias, o passo seguinte é dar sentido aos resultados: o que significa 5 letras por nome de meninas, 5,5 letras por nome de meninos ou 5,3 letras por nome das crianças, e como essas médias podem ajudar a responder à pergunta de pesquisa?

Observamos que o significado da divisão em partes iguais não tem sentido nesta variável. Seria diferente se a variável em estudo fosse "dinheiro para a merenda", quando o todo pode ser repartido em partes iguais e é possível fracionar as unidades de medida. A esse respeito, recomendamos a leitura de Batanero (2000), que explicita os diversos significados das MTC e as principais dificuldades enfrentadas pelas crianças na compreensão dessas medidas.

Neste caso particular, a média pode ser interpretada tanto como um número que representa o conjunto de dados, que nos permite fazer comparações, quanto o centro de gravidade dos dados, utilizando a metáfora da gangorra, pois as crianças sabem que, para brincar, o peso das duas crianças deve ser igual ou muito próximos; caso contrário, ela inclina e não sai do lugar. Se a gangorra estiver solta, pode-se compensar o maior/menor peso deslocando o braço da gangorra até chegar no ponto equilíbrio, logo o professor pode traçar um paralelo com o "fiel da balança", como indica Cobo (2003).

Por essa razão, a representação gráfica da média é realizada utilizando um triângulo tocando a reta numérica (Figura 5), onde podemos observar que, no caso das meninas, a média é exatamente 5 porque 6 das 9 meninas têm nomes com 5 letras, duas têm nomes com três letras ( 2 letras $\times 2=4$ letras a menos) e uma menina tem nome com nove letras (quatro letras a mais), o que compensa os dois nomes curtos, equilibrando a distribuição dos dados. Essa metáfora fica mais complexa no caso dos meninos e da turma, pois os dados se espalham ao longo da amplitude, o que implicaria o cálculo dos desvios dos valores da variável em relação à média e sua soma igual a zero, que está além do escopo dos anos iniciais.

Figura 5 - Tomando a decisão: "quem tem o nome mais curto: meninas ou meninos?

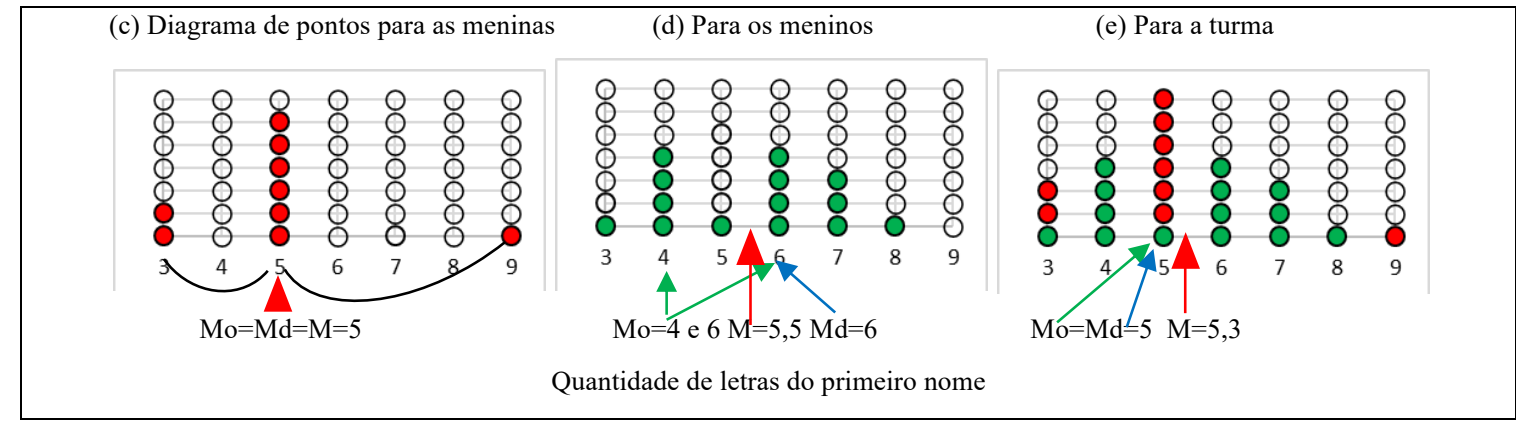

Fonte: construção dos autores. 
Para fechar a análise de dados da $\boldsymbol{S} \mathbf{2}$, o professor pode, junto com as crianças, construir um quadro comparativo para ter uma visão geral dos dados (Quadro 5) e verificar que, dependendo da MTC, podemos chegar às mesmas ou diferentes conclusões e, por isso, é importante ter uma visão da distribuição dos dados para ter maior embasamento.

Quadro 5 - Estatísticas da variável quantidade de letras no $1^{\circ}$ nome

\begin{tabular}{|c|c|c|c|c|c|}
\hline Grupo & $\mathrm{N}$ & $\begin{array}{c}\text { Mínimo; } \\
\text { Máximo }\end{array}$ & $\begin{array}{c}\text { Moda } \\
(\mathrm{Mo})\end{array}$ & $\begin{array}{c}\text { Mediana } \\
(\mathrm{Md})\end{array}$ & $\begin{array}{c}\text { Média } \\
(\mathrm{M})\end{array}$ \\
\hline Meninas & 9 & $3 ; 9$ & 5 & 5 & 5 \\
\hline Meninos & 14 & $3 ; 8$ & 4 e 6 & 6 & 5,5 \\
\hline Turma & 23 & $3 ; 9$ & 5 & 5 & 5,3 \\
\hline
\end{tabular}

Fonte: construção dos autores.

$\mathrm{Na}$ fase da Conclusão (C), além de comunicar os resultados, as crianças devem ser desafiadas a argumentar, de forma escrita e oral, a explicitar as razões para chegar às suas conclusões e qual ou quais MTC utilizarão para formar sua opinião e tomar a decisão.

Nessa tomada de decisão, o professor deve encorajar as crianças a analisarem a distribuição dos dados como um todo e, nesse caso, advogamos o uso do diagrama de pontos, que permite representar as MTC na reta numérica com maior precisão do que o gráfico de barras, por exemplo. Podemos utilizar o triângulo para representar a Média e setas coloridas para representar a Moda e Mediana, sempre tocando os números e, se possível, a reta numérica. Neste exemplo, a Moda nos informa empate, já a Mediana e a Média mostram que as meninas têm o nome mais curto. Logo podemos concluir que, nesta turma, o primeiro nome das meninas é mais curto do que o primeiro nome dos meninos.

Nesta fase, também, as crianças devem ser desafiadas a conjecturar para além dos dados da turma, com perguntas do tipo: e se tivéssemos analisado o nome como um todo, isto é, incluído o segundo nome? Ou se analisássemos o nome das mães ou o nome dos pais? Será que isso mudaria? Enfim, ficam abertas novas frentes de investigação.

Por fim, e a título de ilustração, apresentamos brevemente uma situação tipo 3 (S3), envolvendo a variável contínua altura das crianças, a fim de fazer um contraponto com a variável anterior. Como esta variável toma muitos valores, é preciso que os estudantes percebam a sua distribuição e, para isso, pode-se construir o diagrama de pontos com o próprio corpo das crianças, como realizado por Silva, Magina, Silva (2010), que solicitaram aos estudantes formarem uma fila segundo a altura (Figura 6a); medirem com barbante suas alturas e colarem no quadro (Figura 6b); utilizar o cubo estatístico (Figura 6c) ou, ainda, utilizar o varal com os papeizinhos padronizados. Em todos esses casos, a altura deve estar em ordem crescente 
(decrescente). Para calcular a Mediana, devemos proceder de forma idêntica ao $\boldsymbol{S} \mathbf{2}$ (Figuras $6 \mathrm{~d}$ e 6e), construindo o digrama de pontos para as meninas (Figura 6f), para os meninos (Figura 6g) e para a turma (Figura 6h). Para encontrar a moda será necessário construir a TDF em classes (Figura 6i) e o histograma (Figura 6j). Por fim, resumir os dados e um quadro (Figura $6 \mathrm{k})$.

Para calcular a média basta somar as alturas das meninas e dividir por 9, procedendo de igual modo para os meninos e para a turma. Neste exemplo, verificamos que não tem sentido calcular a Moda, que não existe no caso das meninas e, no caso dos meninos, teríamos três modas, o que não é razoável. Caso se queira, de fato, encontrar a Moda, será necessário construir a TDF em classes e, neste caso, utilizamos intervalos semifechados à esquerda, ou seja, o valor 150 será contado no segundo intervalo, e assim por diante. Neste caso, uma aproximação para a Moda é o ponto médio da frequência modal, que é 12 , logo a Moda será o ponto médio do $3^{\circ}$ intervalo, isto é, $157,5 \mathrm{~cm}(\mathrm{Mo}=(155+160) / 2=157,5)$.

A interpretação dos resultados e a orientação para a condução desse processo devem ser sempre feitas pela realização de perguntas norteadoras, como no caso anterior, cuja pergunta foi: será que as meninas são mais baixas do que os meninos? Como vimos, no caso desta turma, todas as MTC indicam que sim. Neste caso particular, o professor deve lembrar que, ao utilizar as MTC, estamos comparando os grupos, e não cada indivíduo. As estatísticas dizem respeito ao todo!

Figura 6 - Possibilidades para a representação dos dados da variável contínua com material

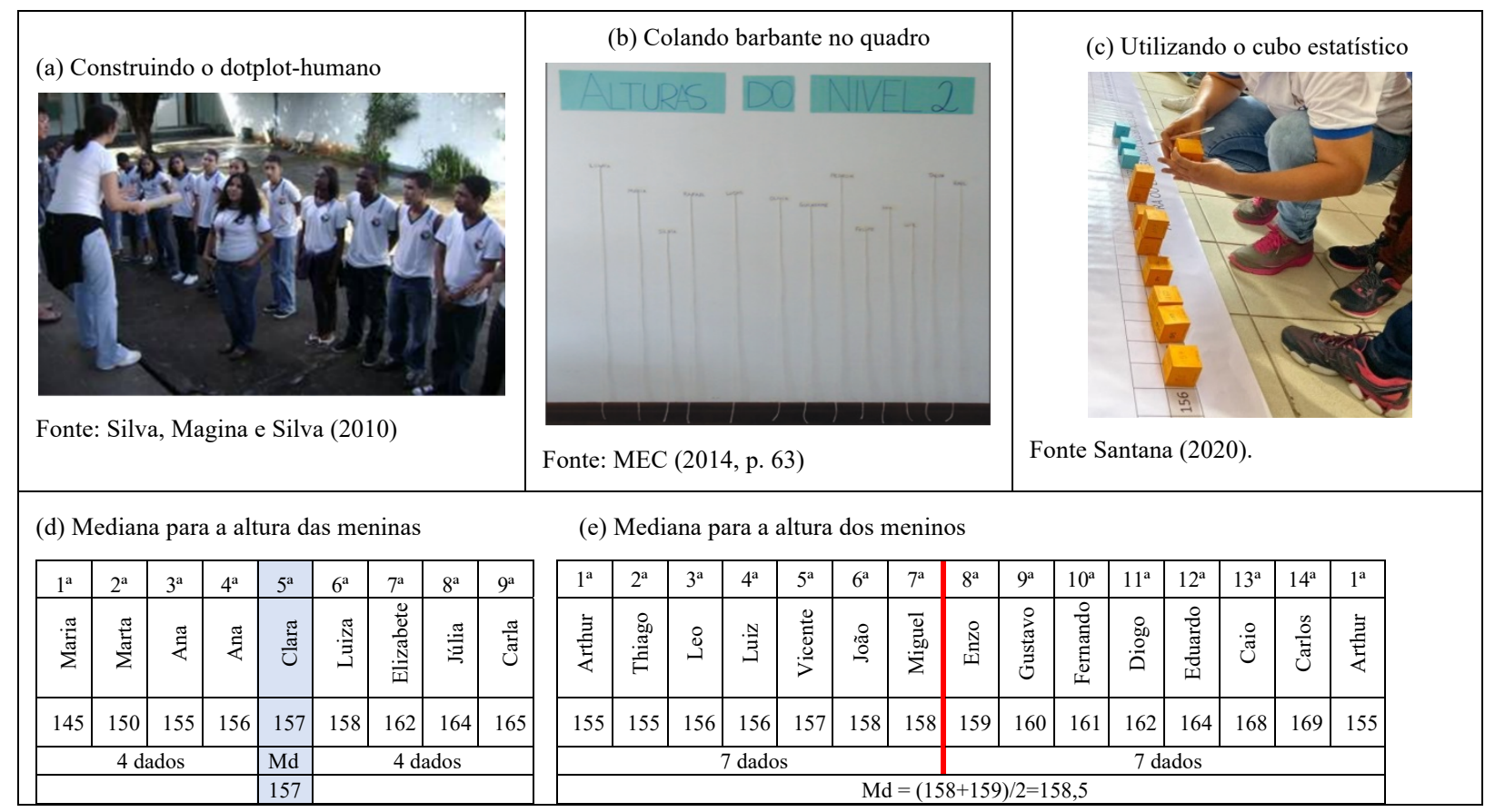


(f) Diagrama de pontos da altura das meninas

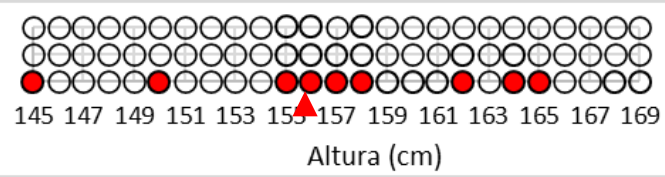

(g) Diagrama de pontos da altura dos meninos

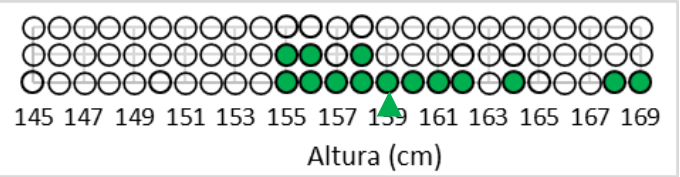

(h) Diagrama de pontos da altura da turma

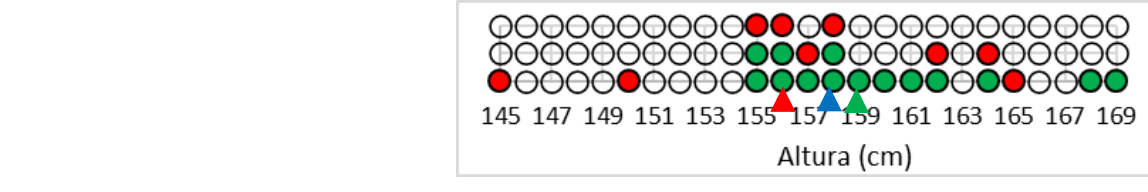

Legenda:

Média das meninas

Média dos Meninos

A Média da Turma

(j) TDF em classes
\begin{tabular}{|l|c|}
\hline Altura (cm) & $\begin{array}{c}\text { Quantidade de } \\
\text { crianças } \\
\text { (frequência) }\end{array}$ \\
\hline$[145 ; 150[$ & 1 \\
\hline$[150 ; 155[$ & 1 \\
\hline$[155 ; 160[$ & $\mathbf{1 2}$ \\
\hline$[160 ; 165[$ & 6 \\
\hline$[165 ; 170[$ & 3 \\
\hline Total & 23 \\
\hline
\end{tabular}

(j) Histograma

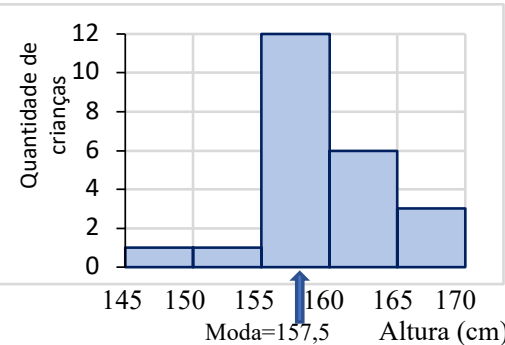

(k) Estatísticas da variável Altura (cm)

\begin{tabular}{|c|c|c|c|c|}
\hline Gênero & Soma & Média & Med. & Moda \\
\hline Meninas & 1412 & 156,9 & 157,0 & - \\
\hline Meninos & 2238 & 159,9 & 158,5 & $?$ \\
\hline Todos* & 3650 & 158,7 & 158,0 & 157,5 \\
\hline
\end{tabular}

Fonte: construção dos autores.

Estas duas situações são prototípicas das MTC para variáveis quantitativas organizadas em dados brutos, possíveis de serem trabalhados nos anos iniciais. Observamos que as fórmulas para encontrar a Média e a Mediana são as mesmas, mas não para a Moda, que pode não existir ou não ter sentido, pois a variável pode tomar distintos valores. No caso da média da $S 2$, poderíamos abreviar os cálculos achando a soma das letras multiplicando o valor pela sua frequência, o que pode não ter sentido na $\boldsymbol{S} 3$. Além disso, na $\boldsymbol{S} 2$ estamos diante do resultado de contagens, como quantidade de irmãos, cujos valores fracionados não têm referente no mundo real e que crianças pequenas terão dificuldade de compreender.

Por limitação de espaço, não podemos apresentar uma situação prototípica $\boldsymbol{S 1}$, envolvendo variáveis qualitativas. Todavia, essas são amplamente trabalhadas na Educação Básica. O percurso é organizar os dados em categorias, construir a TDF em categorias, construir gráficos de barras/colunas/circular, pictogramas e a partir delas encontrar a Moda.

Com estas três situações prototípicas, conseguimos atender o ensino das MTC nos anos iniciais. Desse modo, a seguir tecemos nossas conclusões e considerações finais.

\section{Conclusão e considerações finais}

Neste artigo analisamos as potencialidades e limitações, do ponto de vista teórico, de uma sequência para ensinar as MTC nos anos iniciais do Ensino Fundamental, construída percorrendo as fases do ciclo investigativo, em que as crianças recolhem e analisam seus 
próprios dados utilizando o cubo estatístico como um material concreto manipulável para representar e trabalhar as MTC, tendo como referencial teórico a TCC.

Apresentamos três situações prototípicas para dados brutos a serem trabalhados nos anos iniciais: $\boldsymbol{S} \mathbf{1}$ (variáveis qualitativas); $\boldsymbol{S} \mathbf{2}$ (variáveis discretas que tomam poucos valores); e $\boldsymbol{S} 3$ (variáveis discretas que tomam muitos valores e variáveis contínuas), e exploramos mais amiúde apenas um exemplo da $\boldsymbol{S} \mathbf{2}$ e outro da $\boldsymbol{S} 3$. Ambas as variáveis foram analisadas pelo gênero para dar destaque ao raciocínio inferencial. Para encontrar a Mediana, utilizamos os dados ordenados acompanhados de sua posição, pois isso auxilia a criança na sua compreensão, bem como o diagrama de pontos, que acreditamos ter um enorme potencial por trabalhar com a reta numérica.

Como pode ser visto ao longo da proposta, as crianças têm um papel ativo em todo o processo de investigação, desde a formulação do problema, o preenchimento dos seus dados, a organização em fileiras ou o ordenamento dos cubos até a contagem e a ordenação no registro dos dados. Elas estão atuando o tempo inteiro, interagindo com o professor, seus colegas e o objeto de conhecimento, que não se limita ao "ordene, encontre, some e divida"; mas, ao contrário, as crianças terão a possibilidade de interagir diretamente com os objetos de conhecimento, não apenas das MTC, mas da própria Matemática e da Língua Portuguesa.

Além disso, o uso do cubo estatístico permite à criança acompanhar a transformação de seus dados em estatísticas. Nesse sentido, existem vários trabalhos, como o de Souza (2007), que utilizou fichas, trabalhando as variáveis gênero, idade, gosta da escola, da merenda, como vem para a escola, a que horas vai dormir, com crianças que ainda não estavam alfabetizadas e que entrevistaram seus colegas na escola; Souza e Tinti (2013), que trabalharam com o cubo estatístico e seis variáveis (nome, mês de aniversário, cor que mais gosta, time que torce, quantidade de irmãos e idade); Cazorla, Henriques e Santana (2020), que analisaram o papel dos materiais concretos manipulativos e apresentam outros trabalhos.

Aqui retomamos a indagação feita por Vergnaud (1990b), já citada anteriormente: "Qual é a natureza e a função de um novo conceito, um novo procedimento, um novo tipo de raciocínio, uma nova representação?”. Nesta sequência, todos os conceitos apresentados já são conhecidos e trabalhados na Educação Básica. Contudo, acreditamos que esta organização em situações prototípicas $(\boldsymbol{S} 1, \boldsymbol{S} 2$ e $\boldsymbol{S 3})$ pode auxiliar o professor no reconhecimento e tratamento das variáveis e na escolha de situações a serem trabalhadas com seus alunos.

A identificação dos conceitos, das suas propriedades e representações envolvidas nessas situações é crucial para o desenvolvimento cognitivo das crianças. Além disso, o caráter 
inferencial na perspectiva bivariada, em que o professor se torna um mediador, um fazedor de perguntas-chaves, aguçando a curiosidade, fomentando a observação e a arguição, potencializa esta sequência de ensino para a apropriação das MTC nos anos iniciais.

Observamos que trabalhar nesta perspectiva não é fácil, pois demanda esforço e dedicação do professor, mas encorajamos a sua adoção, pois somente assim estaremos contribuindo para que a Estatística se torne em um instrumento de leitura do mundo e formação de futuros cidadãos que sejam capazes de se situar em um mundo tão desafiador.

\section{Referências}

ALSINA, A.; VÁSQUEZ, C.; MUÑIZ-RODRIGUEZ, L.; RODRIGUEZ-MUÑIZ, L. ¿Cómo promover la alfabetización estadística y probabilística en contexto? Estrategias y recursos. Épsilon - Revista de Educación Matemática, Logroño, n. 104, p. 99-128, 2020.

ANDRADE, V. Os conceitos de Medidas de Tendência Central e de Dispersão na formação estatística no Ensino Médio no Brasil e na França. Abordagem exploratória no quadro da Teoria Antropológica do Didático e da Teoria dos Campos Conceituais. 2013. Tese (Doutorado em Ensino de Ciências) - Universidade Federal Rural de Pernambuco, Recife, 2013.

BATANERO, C. Significado y comprensión de las medidas de tendencia central. UNO, v. 25, p. 41-58, 2000.

BRASIL. Parâmetros Curriculares Nacionais: Matemática. Brasília: MEC, 1997.

BRASIL. Parâmetros Curriculares Nacionais: Matemática. $3^{\circ}$ e $4^{\circ}$ ciclos do Ensino Fundamental. Brasília: MEC, 1998.

BRASIL. Pacto Nacional pela Alfabetização na Idade Certa: Grandezas e Medidas. Brasília: MEC, 2014. https://wp.ufpel.edu.br/obeducpacto/files/2019/08/Unidade-6-3.pdf.

BRASIL. Base Nacional Comum Curricular - BNCC. Educação é a base. Brasília: MEC, 2018.

BUEHRING, R. S. Análise de dados no início da escolaridade: uma realização de ensino por meio dos registros de representação semiótica. 2006. 133 f. Dissertação (Mestrado em Educação Científica e Tecnológica) - Universidade Federal de Santa Catarina, Florianópolis, 2006.

CAZORLA, I.; HENRIQUES, A.; SANTANA, C. O papel dos ostensivos na representação de variáveis estatísticas qualitativas. Bolema, São Carlos, v. 34, p. 1243-1263, 2020. 
CAZORLA, I.; MAGINA, S.; GITIRANA, V.; GUIMARÃES, G. Estatística para os anos iniciais do ensino fundamental. Brasília: Sociedade Brasileira de Educação Matemática SBEM, 2017.

CAZORLA, I.; SANTANA, E.; UTSUMI, M. O campo conceitual da média aritmética: uma primeira aproximação conceitual. Revemat, Florianópolis, v. 14, Edição Especial Educação Estatística, p. 1-21, 2019.

CAZORLA, I.; UTSUMI, M.; MONTEIRO, C. Variáveis estatísticas e suas representações em gráficos: reflexões para seu ensino. Números, Tenerif, v. 106, p. 23-32, 2021.

CHICK, H. Tools for transnumeration: early stages in the art of data representation. In: PUTT, I.; FARAGHER, R.; MCLEAN, M. (Eds.). Proceedings of the 27th Annual Conference of the Mathematics Education Research Group of Australasia (p. 167-174). Sydney: MERGA, 2004.

COBO, B. Significados de las medidas de posición central para los estudiantes de secundaria. 2003. Tese (Doutorado) - Universidade de Granada. 2003. https://www.ugr.es/ batanero/pages/ARTICULOS/tesiscobo.pdf.

COBO, B.; BATANERO, C. La mediana en la educación secundaria obligatoria: ¿un concepto sencillo? UNO, v. 23, p. 85-96, 2000.

FIGUEIREDO, T. Mediana e quartis: um caso de estudo das dificuldades de aprendizagem de alunos do 8. ${ }^{\circ}$ ano de escolaridade. 2017. Dissertação (Mestrado em Matemática para professores) - Universidade de Aveiro]. 2017. Disponível em: https://ria.ua.pt/bitstream/10773/21920/1/Disserta\%C3\%A7\%C3\%A3o_Teresa_Figueiredo.p df.

MAGINA, S.; LAUTERT, S.; CAZORLA, I. A Teoria dos Campos Conceituais na sala de aula. In: MAGINA; SPINILO; LAUTERT (Orgs.). Processos Cognitivos e Linguísticos na Educação Matemática. Teorias, Pesquisas e Salas de Aula (in press).

MAKAR, K.; RUBIN, A. A framework for thinking about informal Statistical inference. Statistics Education Research Journal, v. 8, n. 1, p. 82-105, 2009. https://www.stat.auckland.ac.nz/ iase/serj/SERJ8(1).pdf\#page=85.

MAYÉN, S.; COBO, B.; BATANERO, C.; BALDERAS, P. Comprensión de las medidas de posición central en estudiantes mexicanos de bachillerato. Unión, v. 9, p. 187-201, 2017. http://www.fisem.org/www/union/revistas/2007/9/Union_009_016.pdf.

OLIVEIRA, T. Contribuições das disciplinas de estatística na formação do futuro professor de Matemática para a Educação Básica. 2020. Dissertação (Mestrado em Educação Matemática) - Universidade Estadual de Santa Cruz, Santa Cruz, 2020. 
SANTANA, C. Relações entre variáveis estatísticas na contextualização e apropriação da função afim. 2020. Dissertação (Mestrado em Educação Matemática) - Universidade Estadual de Santa Cruz, Santa Cruz, 2020.

SILVA, C.; MAGINA, S.; SILVA, E. Homem Vitruviano. In: CAZORLA, I.; SANTANA, E. (Orgs.). Do Tratamento da Informação ao Letramento Estatístico. Itabuna: Via Litterarum, 2010. pp. 80-93.

SOUZA, A. C. A Educação Estatística na infância. 2007. Dissertação (Mestrado em Educação Matemática) - Unicsul, São Paulo, 2007.

SOUZA, M.; TINTI, D. O laboratório de ensino de Matemática e o ensino de Estatística: socializando reflexões e possibilidades a partir de uma vivência no curso Licenciatura em Matemática. In: Encontro Nacional de Educação Matemática, 2013, Curitiba. Anais... Curitiba: SBEM, 2013. p. 1-9. Disponível em: http://sbem.iuri0094.hospedagemdesites.ws/anais/XIENEM/pdf/3094_1728_ID.pdf.

VERGNAUD, G. A Classification of Cognitive Tasks and Operations of Thought Involved in Addition and Subtraction Problems. In. Addition and Subtraction: a cognitive Perspective. New Jerssey: Lawrense Erlbaun, 1982. p. 39-59.

VERGNAUD, G. Didactics as a Content-oriented Approach to Research on the Learning of Physics, Mathematics and Natural Language. New Orleand: AERA, 1984, p. 1-22.

VERGNAUD, G. Conclusion. In: JANVIER, C. (Ed.). Problem of Representation in the Teaching and Learning of Mathematics. London: LEA publishers. 1987, p. 227-232.

VERGNAUD, G. La théorie des champs conceptuels. Recherches en Didactique des Mathématiques, Grenoble, v. 10, n. 23, p. 133-170, 1990a.

VERGNAUD, G. Epistemology and Psychology of Mathematics Education. In NESHER, P.; KILPATRICK, J. Cognition and Practice. Cambridge: Cambridge University Press, 1990b. p. 14-30.

VERGNAUD, G. A Teoria dos Campos Conceituais. In: J. Brun. Didáctica das matemáticas. Lisboa: Instituto Piaget, 1996, p. 155-191.

WILD, C.; PFANNKUCH, M. Statistical thinking in empirical enquiry. International Statistical Review, 1999, v. 67, p. 223-265. https://doi.org/10.1111/j.17515823.1999.tb00442.x. 